\title{
Modeling of ice flow and internal layers along a flowline through Swiss Camp, West Greenland
}

\author{
W. L. Wang, ${ }^{1}$ H. J. Zwally, ${ }^{2}$ W. Abdalati, ${ }^{3}$ S. Luo ${ }^{4}$ \\ ${ }^{1}$ Raytheon ITSS, NASA Goddard Space Flight Center, Code 971, Greenbelt, MD 20771, U.S.A. \\ ${ }^{2}$ Oceans and Ice Branch, NASA Goddard Space Flight Center, Code 971, Greenbelt, MD 20771, U.S.A. \\ ${ }^{3}$ NASA Headquarters, Code TS, 300 E St. SW, Washington, DC 20546, U.S.A. \\ ${ }^{4}$ NVI Inc., NASA Goddard Space Flight Center, Code 971, Greenbelt, MD 20771, U.S.A.
}

\begin{abstract}
An anisotropic-ice flowline model is applied to a flowline through Swiss Camp $\left(69.57^{\circ} \mathrm{N}, 49.28^{\circ} \mathrm{W}\right)$, West Greenland, to estimate the dates of internal layers detected by radio-echo sounding measurements. The effect of an anisotropic-ice fabric on ice flow is incorporated into the steady-state flowline model. The stress-strain-rate relationship for anisotropic ice is characterized by an enhancement factor based on the laboratory observations of ice deformation under combined compression and shear stresses. By using present-day data of accumulation rate, surface temperature, surface elevation and ice thickness along the flowline as model inputs, a very close agreement is found between the isochrones generated from the model and the observed internal layers with confirmed dates. The results indicate that this part of the Greenland ice sheet is primarily in steady state.
\end{abstract}

\section{INTRODUCTION}

Radio-echo sounding (RES) has been used to investigate the subsurface properties (internal structure) of ice over large areas of the Antarctic and Greenland ice sheets. Internal layering from RES measurements (Fig. 1) provides a vertical profile in an ice sheet, which could previously be obtained only from drilled boreholes. The radar echoes arising from internal layers in ice are caused by the sudden changes in complex dielectric permittivity of layers in the ice sheets (Fujita and others, 1999). The mechanisms causing the sudden changes have been examined in detail, and changes in shallow layers have been attributed primarily to ice-density variations. Changes in deeper layers have mainly been assigned to changes in electrical conductivity due to acidic fallout from volcanic eruptions and/or changes in impurity concentration associated with climatic transitions (Harrison, 1973; Paren and Robin, 1975; Clough, 1977; Hammer, 1980; Millar, 1981; Moore, 1988; Fujita and Mae, 1994; Fujita and others, 1999). Variation of ice-crystal orientation can also cause the changes in permittivity at the large depth of the ice sheet (Harrison, 1973; Fujita and Mae, 1994; Fujita and others, 1999).

RES-detected internal layers are widely recognized as isochrones: former ice-sheet surfaces that have been buried and deformed by ice flow (Whillans, 1976; Clough, 1977; Hammer, 1980; Dahl-Jensen and others, 1997; Morse and others, 1998; Nereson and others, 2000). As such, they would contain information about the ice-sheet history, from which inferences can be made about some of the climate changes. For example,

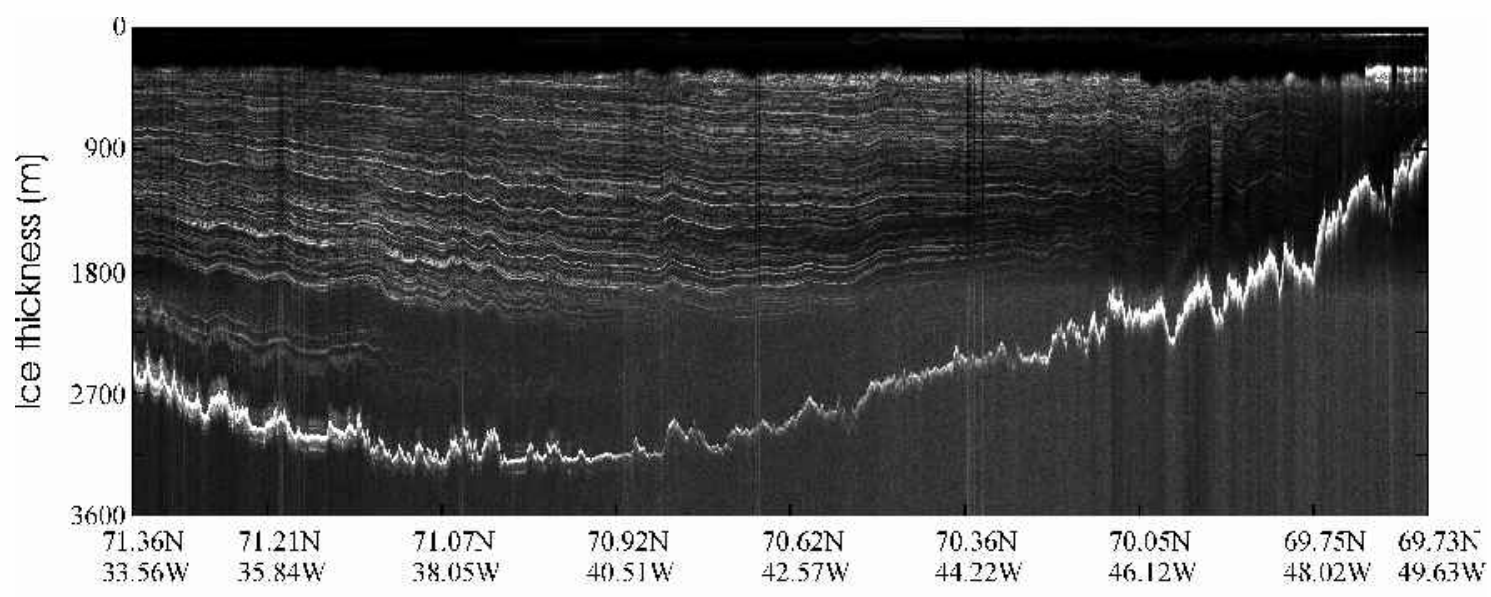

Geo-location

Fig. 1. RES imagery showing internal layers along the airborne flight-line indicated by dashed line in Figure 2. 
known ages of internal layers enabled past accumulations to be inferred from the horizontal variation in thickness between the layers on Taylor Dome, East Antarctica (Morse and others, 1998), and around Summit, Greenland (DahlJensen and others, 1997; Fahnestock and others, in press). Lacking time information, Nereson and others (2000) estimated the pattern of accumulation over Siple Dome, West Antarctica, from the observed pattern of internal layering.

The most common method of dating the internal layers is to combine them with annual-layer thickness measurements from the associated ice cores. A recently developed system (Fahnestock and others, in press) traces the internal layers from RES imageries and then extends the ages of the layers at the Greenland Icecore Project (GRIP) ice-core site at the Summit of the Greenland ice sheet, based upon the available GRIP age-depth relationship (Johnsen and others, 1997), to the same layers along the airborne flightlines. The dated internal layers mainly cover the northern areas of the Greenland ice sheet (W. Abdalati, unpublished information), providing a good reference to validate the numerical model calculation. In regions where the internal layers cannot be detected or cannot be extended from the dated ice cores (e.g. the ablation zone), numerical modeling may give a good approximation of the ice age at any icesheet depth.

In this paper, we apply the anisotropic-ice flowline model developed by Wang and Warner (1999) to a flowline through Swiss Camp (69.57 $\left.\mathrm{N}, 49.28^{\circ} \mathrm{W}\right)$, West Greenland, to estimate the dates of internal layers obtained by the RES technique (Fahnestock and others, in press). The available measurements of dated internal layers are used to validate the model calculation.

\section{THE MODEL}

The model used here is an anisotropic steady-state ice flowline model (Wang and Warner, 1999). The stress-strain-rate relationship for anisotropic ice is characterized by an enhancement factor, defined as the ratio of tertiary strain rate for anisotropic ice to minimum strain rate for isotropic ice, based on the laboratory observations of ice deformation under combined compression and shear stresses (Li and others, 1996). The model has been described in detail by Wang and Warner (1999). Here we give a brief review of the flow relations used in the model to describe anisotropic-ice flow.

In this two-dimensional model, the horizontal transverse flow is neglected so that the flow is entirely constrained to the vertical compression and horizontal shear along the flowline in steady-state balance. If $x$ denotes the direction of flow and $z$ the vertical direction, the flow relations between strain rate and stress for components of shear and compression are

$$
\begin{aligned}
\dot{\varepsilon}_{x z} & =G\left(\lambda_{\mathrm{c}}\right) A_{0}(T) \tau_{\mathrm{o}}{ }^{2} \tau_{x z} \\
\dot{\varepsilon}_{z} & =F\left(\lambda_{\mathrm{c}}\right) A_{0}(T) \tau_{\mathrm{o}}{ }^{2} \tau_{z}^{\prime},
\end{aligned}
$$

where $\dot{\varepsilon}_{x z}$ is shear strain rate, $\dot{\varepsilon}_{z}$ is compressive strain rate, $A_{0}(T)$ is a temperature-dependent parameter, $T$ is temperature, $\tau_{\mathrm{o}}$ is octahedral shear stress, $\tau_{x z}$ is shear stress, $\tau_{z}^{\prime}$ is compressive deviatoric stress, $G\left(\lambda_{\mathrm{c}}\right)$ and $F\left(\lambda_{\mathrm{c}}\right)$ are enhancement factors of shear and compression component, respectively, and $\lambda_{\mathrm{c}}$ is a compression factor defined as

$$
\lambda_{\mathrm{c}}=\tau_{z}^{\prime} /\left(\tau_{x z}^{2}+\tau_{z}^{\prime 2}\right)^{1 / 2} .
$$

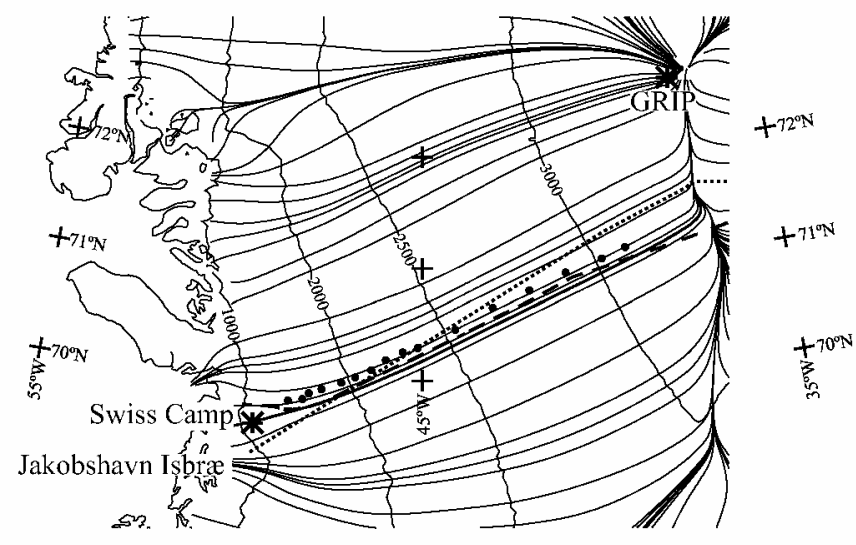

Fig. 2. Map of flowlines in West Greenland, with the contours of surface elevation in meters. Thick line shows the studied flowline through Swiss Camp station; dashed line shows the airborne flight-line; dotted line shows the Expéditions Glaciologiques Internationales au Groenland (EGIG) traverse-line surface velocity observations (Hofmann, 1975); solid circles show locations of the measured accumulation (Benson, 1962) and temperature (Mock and Weeks, 1966); and asterisks show the sites of the GRIP borehole and Swiss Camp station.

Laboratory experiments indicate that $G\left(\lambda_{\mathrm{c}}\right)$ and $F\left(\lambda_{\mathrm{c}}\right)$ can be simplified to be equal to $E\left(\lambda_{\mathrm{c}}\right)$ ( $\mathrm{Li}$ and others, 1996) according to:

$$
E\left(\lambda_{\mathrm{c}}\right)=E_{\mathrm{s}}\left(E_{\mathrm{c}} / E_{\mathrm{s}}\right)^{\lambda_{\mathrm{c}}}, \quad E_{\mathrm{s}}=10 \text { and } E_{\mathrm{c}}=3,
$$

where $E_{\mathrm{s}}$ and $E_{\mathrm{c}}$ are respective enhancement factors for shear or compression alone. While $\lambda_{\mathrm{c}}$ varies from 1 to 0 as the stress situation varies from purely confined compression (shear stress $\tau_{x z}=0$ ) to simple shear (compressive deviatoric stress $\tau_{z}^{\prime}=0$ ), enhancement factor $E\left(\lambda_{\mathrm{c}}\right)$ increases from 3 to 10 .

In Equations (1) and (2), the temperature-dependent coefficient $A_{0}(T)$ is based on the laboratory experiment results (Budd and Jacka, 1989) tabulated by Wang and Warner (1998, table 2) which have similar values calculated from the Arrhenius relation (Paterson, 1994). The shear stress is taken as the driving stress

$$
\tau_{x z}=\rho g \alpha Z
$$

in terms of the ice density $\rho$, the acceleration due to gravity $g$, the depth $Z$ and the surface slope $\alpha$. The octahedral shear stress is taken as

$$
\tau_{\mathrm{o}}=\left[\frac{2}{3}\left(\tau_{x z}^{2}+\tau_{z}^{\prime 2}\right)\right]^{1 / 2},
$$

assuming the ice flow corresponds to a confined vertical compression stress combined with a horizontal shear stress.

After rearranging the above equations, a cubic equation for the shear strain rate, $\dot{\varepsilon}_{x z}$, is obtained as

$$
\dot{\varepsilon}_{x z}^{3}-\frac{2}{3} E\left(\lambda_{\mathrm{c}}\right) A_{0}(T) \tau_{x z}^{3}\left(\dot{\varepsilon}_{x z}^{2}+\dot{\varepsilon}_{z}^{2}\right)=0
$$

This equation involves vertical compressive strain rate, $\dot{\varepsilon}_{z}$, which can be calculated from horizontal velocity based on the assumption that ice is incompressible.

Equation (7) is the stress-strain-rate relation for anisotropic-ice flow used in the flowline model and solved iteratively for the shear strain rate (see Wang and Warner, 1999). 

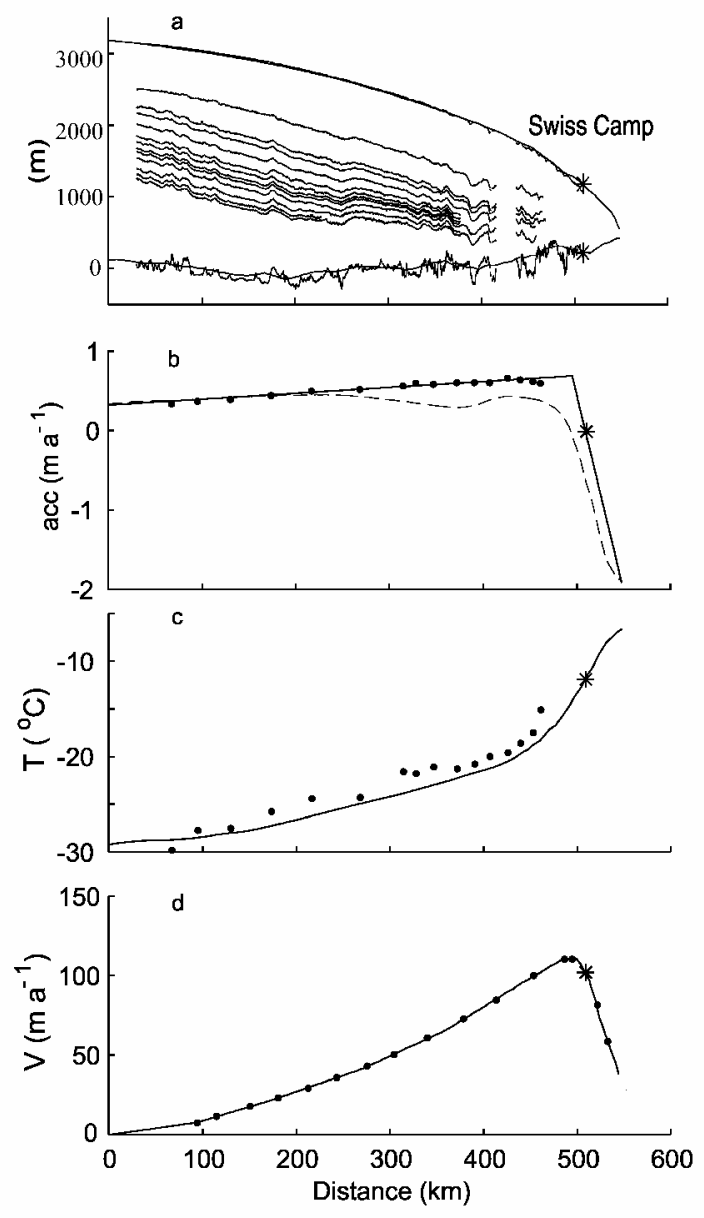

Fig. 3. Profiles of input data used in the model, with the location of Swiss Camp station indicated by asterisk. (a) Flowline topography (smoothed curves) used in the model, the measured topography from airborne flight (rough curves) and internal layers (thin lines) representing the ages in Table 1. (b) Surface accumulation rates: dots indicate previous measurements (Benson, 1962) at the locations shown in Figure 2, the dashed line is interpolated from $50 \mathrm{~km}$ grid database (Zwally and Giovinetto, 2000) and the solid line is the trend of profile used in the model. (c) Surface temperatures: dots indicate previous measurements (Mock and Weeks, 1966) at the locations shown in Figure 2, and solid line is interpolated from $50 \mathrm{~km}$ grid database (personal communication from M. B. Giovinetto, 2001) used in the model. (d) Surface horizontal velocities: dots indicate the measurements (Hofmann, 1975) along EGIG traverse line shown in Figure 2, asterisk shows the observation at Swiss Camp site and the solid line is the profile used in the model.

\section{APPLICATION OF THE MODEL TO THE FLOWLINE}

Flowlines over the whole Greenland ice sheet were generated based on the assumption that the ice flows downslope in the direction perpendicular to the surface contours using $5 \mathrm{~km}$ gridded surface elevations derived from European Remote-sensing Satellite (ERS-1) radar altimeter data (Zwally and Brenner, 2001). The flowline studied in this paper (Fig. 2), from the ice-divide ridge through the Swiss Camp station northwestward to the coast, was chosen because an airborne radar survey ran very close to the flowline. The internal layers were traced from RES imagery (Fig. 1) along the flight-line and were dated by extending the same layers from the Greenland Icecore Project (GRIP)
Table 1. Ages of the internal layers displayed in Figures 3 a and 4

\begin{tabular}{lccc}
\hline Layer & $\begin{array}{c}\text { Age } \\
\text { years }\end{array}$ & Layer & $\begin{array}{c}\text { Age } \\
\text { years }\end{array}$ \\
\hline 1 & & & \\
\hline 2 & 2339 & 7 & 7074 \\
3 & 3614 & 8 & 7462 \\
4 & 4004 & 9 & 8480 \\
5 & 4866 & 10 & 10166 \\
6 & 5875 & 11 & 11013 \\
& 6225 & 12 & 12329 \\
\hline
\end{tabular}

ice-core site where dating was available, which were used to validate the model calculation. Furthermore, the previous filed observations, such as surface velocity (Hofmann, 1975), accumulation (Benson, 1962) and temperature (Mock and Weeks, 1966), were available near this flowline and provided the input data to the model.

The Swiss Camp $\left(69.57^{\circ} \mathrm{N}, 49.28^{\circ} \mathrm{W}\right)$, located in westcentral Greenland, was established near the equilibrium line in 1990, estimated from surface balance measurements of the 1980s. The surface mass balance has been studied by means of global positioning system measurements. The modeling study along the flowline through Swiss Camp provides information about the internal dynamics of ice in the vicinity of the Camp.

Figure 3 shows the data profiles used as inputs to the flowline model. Swiss Camp station is $510 \mathrm{~km}$ from the ice divide along the direction of flow.

The ice-sheet topography along the studied flowline is shown in Figure 3a. Surface elevations used in the model were taken from $5 \mathrm{~km}$ grid satellite radar altimeter data (Zwally and Brenner, 2001), and bedrock elevation by subtracting ice thickness (Bamber and others, in press) from the surface elevation. Surface and bedrock profiles obtained from RES measurements along the flight-line are plotted in Figure $3 \mathrm{a}$ in the section with the observed internal layers. Comparisons with the RES measurements show the irregular basal topography, but the profile from the $5 \mathrm{~km}$ grids appears reasonably to represent the smoothed topography incorporated into the model.

Twelve internal layers are traced from RES imagery (Fig. 1) and displayed in Figure $3 \mathrm{a}$. The discontinuous internal layers $410-430 \mathrm{~km}$ from the ice divide are due to unclear RES imagery in this section, but the pattern is then resumed beyond $430 \mathrm{~km}$. The corresponding ages of the layers shown, obtained by tracing the continuous layers back to the dated GRIP core site, vary from 2339 to 12329 years (see Table 1).

Internal layers along the flowline seem to reflect the shape of the bedrock undulation with decreasing amplitude as the distance from the bedrock increases. This can be seen more clearly in Figure 1. Near the Greenland Summit along the ice-divide ridge, however, where the bedrock is smooth, the internal oscillations are caused by variations of the dynamic velocity fields rather than the bedrock undulations (DahlJensen and others, 1997).

Surface accumulation rate along the flowline used in the model is a trend line shown in Figure 3b. This was determined based on the previous observations (Benson, 1962) at the locations near the flowline (see Fig. 2) and $50 \mathrm{~km}$ grid database (Zwally and Giovinetto, 2000). The accumulation rate is zero at Swiss Camp station on the equilibrium line 
and is negative at the lower elevations where ablation exceeds precipitation.

The surface temperature profile, shown by the solid line in Figure 3c, was interpolated from a $50 \mathrm{~km}$ grid database (personal communication from M. B. Giovinetto, 2001), showing a good agreement with the previous observations (Mock and Weeks, 1966) near the flowline (see Fig. 2).

The surface velocity profile (Fig. 3d) is assumed to be the observations along the EGIG traverse line (Hofmann, 1975), which runs close to the flowline studied in this paper (see Fig. 2), based on the assumption that surface horizontal velocities along the flowlines vary slowly along the surface elevation contour lines. Using laboratory-based flow relations results in an overestimate of surface velocity $(\sim 8$ times too high) by integrating shear strain rate down to the bedrock. This is because the model does not consider the reduction of enhancement and shear stress near the bedrock. This reduction may cause the reduced shear strain rates near the bedrock which have been found from several of the borehole inclination measurements in Antarctica (e.g. Russell-Head and Budd, 1979; Etheridge, 1989; Morgan and others, 1998). In Greenland it has been found at Dye 3 borehole (DahlJensen, 1985; Dahl-Jensen and Gundestrup, 1987) that maximum shear strain rates occur at the bottom due to a high concentration of dust and other impurities, but at $200-257 \mathrm{~m}$ depth above the bed the shear strain rates are almost constant along with the reduction of the enhancement factors. To compensate for the overestimated velocity without turning any parameter in the flow law, we adopted a reasonably simple scheme from Wang and Warner (1999) by terminating integration of shear strain rate near the bedrock to match the measured surface velocity.

Basal sliding velocity was estimated based on the study of the ice-sheet modeling along a flowline jointed with the central flowline of Jakobshavn Isbræ drainage basin (see Fig. 2) (Funk and others, 1994) using the Huybrechts and de Wolde (1999) equation

$$
V_{\text {sliding }}=A_{\mathrm{s}} \frac{\tau_{\mathrm{b}}^{3}}{Z^{*}}
$$

where a constant $A_{\mathrm{s}}=1.8 \times 10^{-10} \mathrm{~N}^{-3} \mathrm{a}^{-1} \mathrm{~m}^{8}, \tau_{\mathrm{b}}$ is basal shear stress and $Z^{*}$ is the height above buoyancy.

All input data were interpolated so that the horizontal resolution was $1 \mathrm{~km}$. A rescaled vertical coordinate was used by subdividing the ice thickness into 100 evenly spaced bands. The basal temperature gradient of $0.02{ }^{\circ} \mathrm{C} \mathrm{m}^{-1}$ (Kostecka and Whillans, 1988; Funk and others, 1994) was used in the calculation of the steady-state temperature.

\section{RESULTS AND DISGUSSION}

\subsection{Comparison of modeled isochrones with observed internal layers}

The ages of the ice at any depth of the ice sheet along the flowline were determined by numerically integrating the velocity fields following the ice-particle trajectories from the surface, using the present-day surface accumulation rates and assuming a steady-state ice flow.

Several isochrones calculated from the model are displayed in Figure 4 to compare with the observed internal layers. Using the smoothed bedrock and a trend surface accumulation rate results in smoothed modeled isochrones which

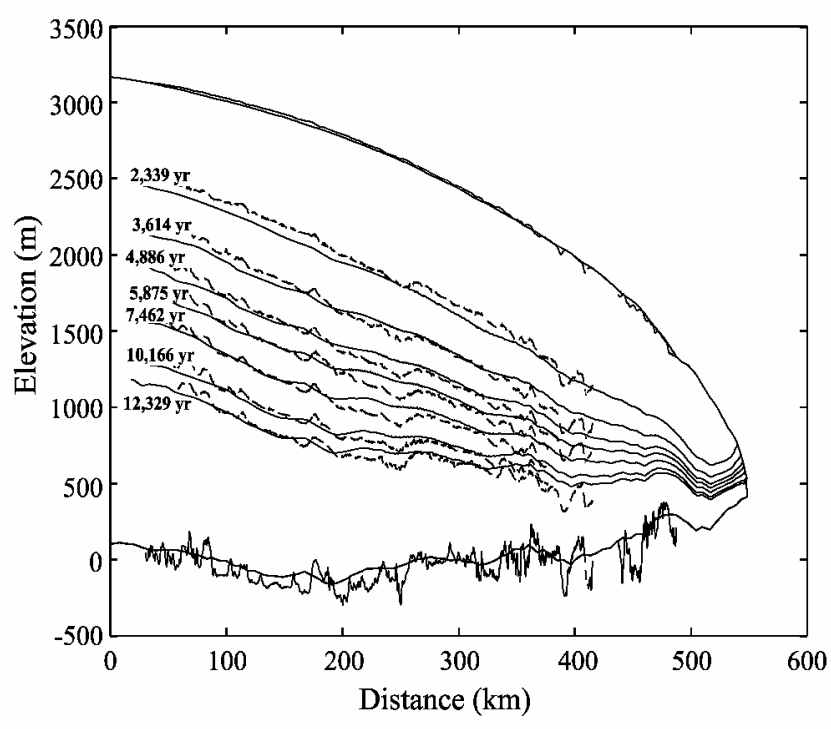

Fig. 4. Isochrones (solid lines) calculated from the model, and observed internal layers (dashed lines) traced from RES imagery (Fig. 1). Surface and bedrock elevations used in the model are plotted in smoothed curves, and the RES observations in rough curves.

do not capture the high-frequency oscillations of the observed internal layers, but agree quite well on larger scales.

The model simulating isotropic-ice flow has been run by replacing the flow relation for anisotropic ice with the relation for isotropic ice, i.e. using Equation (7) with $E\left(\lambda_{c}\right)=1$ in the model calculations. Under all of the same conditions, the isochrones calculated from the model for isotropic-ice flow do not match the observed internal layers well (see Figs 5 and 6a).

Figure 5 gives a quantitative expression of the ages computed from the models for both anisotropic and isotropic ice

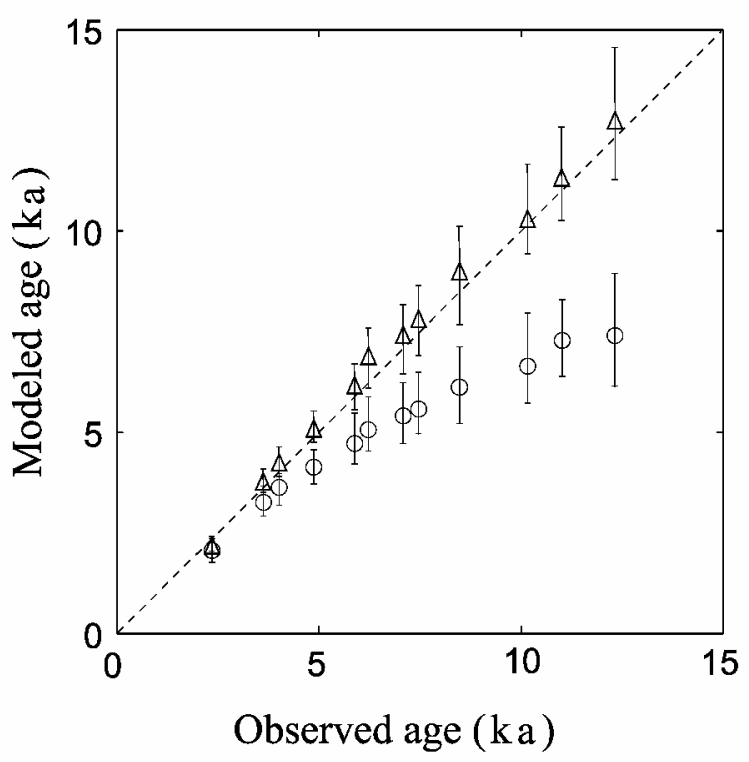

Fig. 5. Plot of the ages computed from the models against observed ages from the layer measurements. Open triangles and open circles indicate mean values of computed ages from the models for anisotropic and isotropic ice, respectively, along each measured layer. Bars show the range of variations between computed and observed ages along each layer. The dashed line indicates the ideal match situation. 

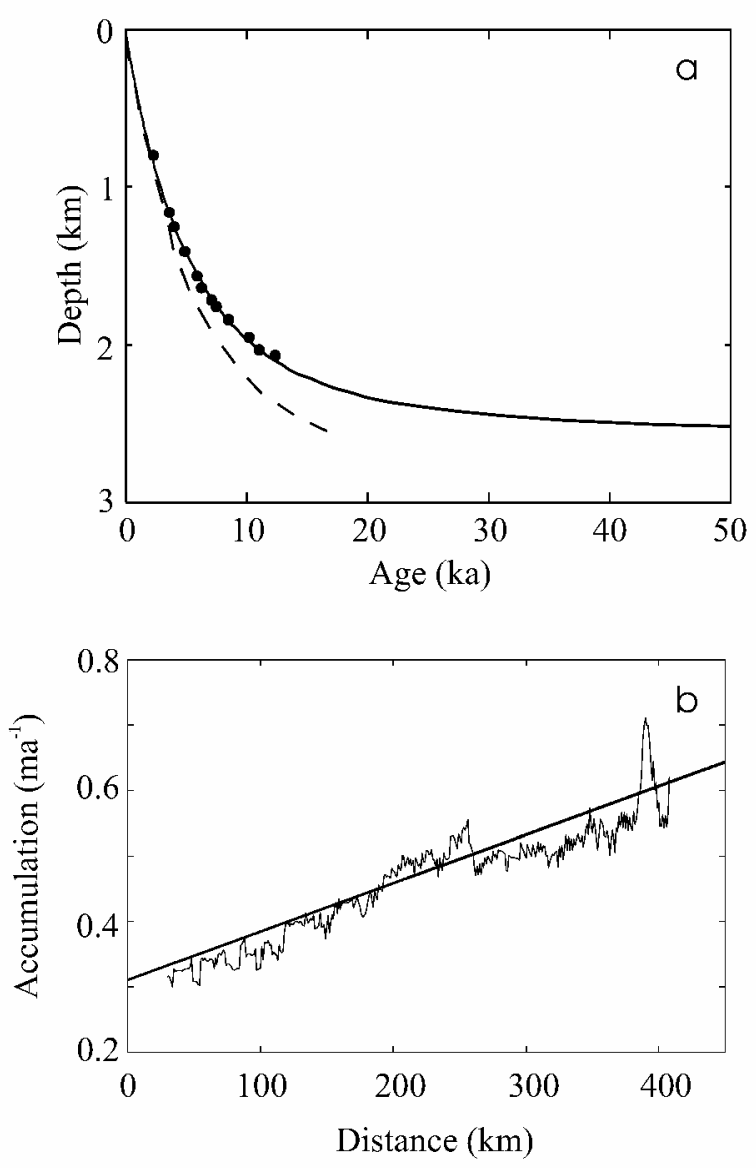

Fig. 6. (a) Relation of age and depth, at $200 \mathrm{~km}$ from the ice divide, generated from the models for anisotropic-ice flow (solid line) and using Equation (7) with $E\left(\lambda_{\mathrm{c}}\right)=1$ for isotropic-ice flow (dashed line), and from the observed internal layers (solid circles). (b) Surface accumulation rate used in the model (thick line) and reconstructed from the observed internal layer nearest the surface of the ice sheet with 2339 years (thin line).

with the ages obtained from GRIP cores for 12 observed internal layers. The modeled ages at the depths of the observed horizons are calculated as a function of $x$ and shown in the bars. The mean values are obtained by averaging those modeled ages along each observed layer. The larger error bars in lower layers are caused by the bedrock undulation, which will be substantially reduced by using flight-line bedrock (rough curve in Fig. 4) in the models. Figure 5 shows the importance of including anisotropy in ice-flow modeling.

\subsection{Relation of age and depth, and reconstructed surface accumulation rates}

The comparison of the relations of age and depth derived from the model results with the observations is shown in Figure $6 \mathrm{a}$ for a point $200 \mathrm{~km}$ from the ridge. All three profiles in Figure 6a closely agree for approximately the top one-third of the ice thickness. At greater depth, the modeled profile for anisotropic ice still follows the observations closely, in contrast with the obvious departure shown by the dashed line for isotropic ice, which indicates that isotropic ice is no longer appropriate when anisotropy of the icecrystal fabric develops with increasing depth and that it is important to consider the effect of the ice-crystal anisotropy on the modeling of ice flow in the deeper parts of ice sheets.

Based on the assumption of steady-state ice flow, we recon-
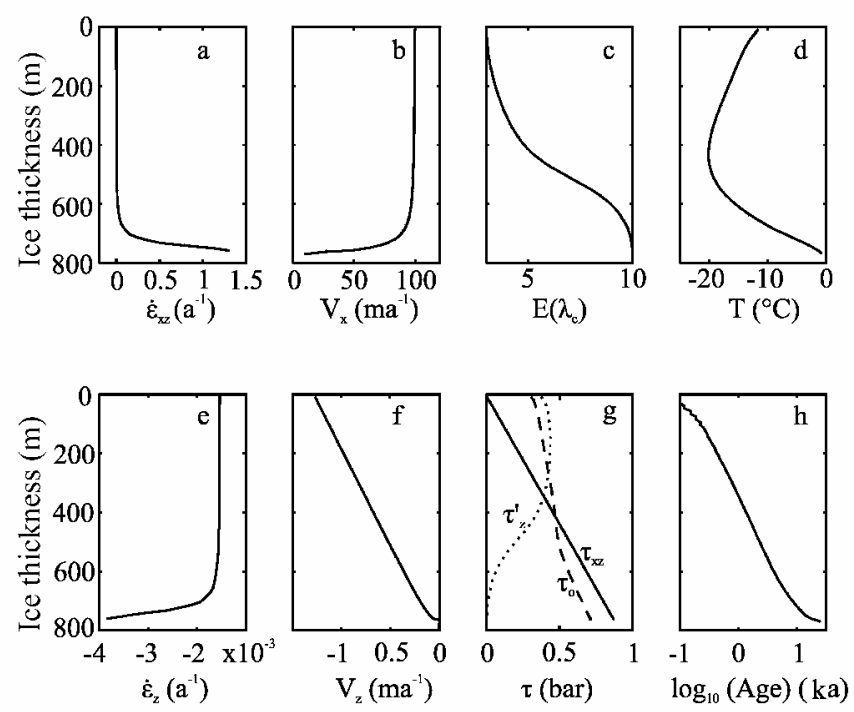

Fig. 7. Vertical profiles of several outputs from the model at Swiss Camp station, $510 \mathrm{~km}$ from the ice divide: (a) shear strain rate $\left(\dot{\varepsilon}_{x z}\right) ;(b)$ horizontal velocity $\left(V_{x}\right) ;(c)$ enhancement factor $\left(E\left(\lambda_{\mathrm{c}}\right)\right)$; (d) temperature $(T)$; (e) vertical compressive strain rate $\left(\dot{\varepsilon}_{z}\right) ;(f)$ vertical velocity $\left(V_{z}\right) ;(g)$ shear stress $\left(\tau_{x z}\right)$, compression stress deviator $\left(\tau_{z}^{\prime}\right)$ and octahedral shear stress $\left(\tau_{\mathrm{o}}\right)$; and $(h)$ age.

structed the accumulation rates for the internal layer nearest to the surface of the ice sheet with 2339 years. The age-depth relation given in Figure $6 \mathrm{a}$ and the modeled vertical strain were used in the calculation. The reconstructed accumulation rates are close to the present-day values (see Fig. 6b), confirming that this part of the Greenland ice sheet has not experienced major changes in accumulation rate and ice-flow status.

\subsection{Ice flow at Swiss Camp station at/near the equi- librium line}

In this study, present-day surface accumulation rate, surface temperature, surface elevation, ice thickness and surface velocity were used as model inputs. The ice-flow regime through the depth was modeled along the flowline. The agreement between the modeled isochrones and the observed internal layers implies that the model incorporated with ice-crystal fabric anisotropy has given a proper description of the ice flow. Here, we use Swiss Camp site, at or near the equilibrium line, as an example of the modeling results. The mass balance of the Greenland ice sheet at Swiss Camp site will be studied based on these results and the surface observations.

Vertical profiles of several outputs from the Swiss Camp model are summarized in Figure 7. The parameters shown are: shear and vertical compressive strain rates, horizontal and vertical velocities, enhancement, stresses, temperature and age.

Shear strain rates $\left(\dot{\varepsilon}_{x z}\right)$ increase with depth, which is accompanied by an increased enhancement $\left(E\left(\lambda_{\mathrm{c}}\right)\right)$ from 3 to 10 , as the range of stress regimes changes from predominantly vertical compressive stress $\left(\tau_{z}^{\prime}\right)$ in the upper layers to predominantly horizontal shear stress $\left(\tau_{x z}\right)$ near the bed. The transition layer from the compression stress dominance to the shear stress dominance is about $300 \mathrm{~m}$ deep (Fig. $7 \mathrm{~g}$ ).

It is important to note the following points: 
(1) Since accumulation rate is zero at the site, the vertical velocities $\left(V_{z}\right)$ represent the total horizontal advections.

(2) Temperature profile $(T)$ shows that the bottom ice reaches the melting point, indicating the existence of basal sliding.

(3) The age-depth profile (Fig. 7h) shows that the ice near the bottom is $>20000$ years old.

\section{GONGLUSION}

The application of an anisotropic steady-state ice flowline model to the flowline in West Greenland is presented in this paper. A close agreement is found between the isochrones generated from the model using present-day input data and observed internal layers with confirmed dates, and this strong agreement indicates that this part of the Greenland ice sheet is essentially in steady state. This part of the ice sheet has been close to its present form for a period of at least 12000 years. This successful comparison shows that the model provides a good approximation of the flow of the ice sheet, and that the ice-crystal fabric anisotropy must be considered in order to accurately model deeper ice flow.

\section{ACKNOWLEDGEMENT}

We wish to thank M. Beckley for the help with the graphics.

\section{REFERENGES}

Bamber, J. L., R. Layberry and S. P. Gogineni. In press. A new ice thickness and bed data set for the Greenland ice sheet. 1. Measurement, data reduction, and errors. F. Geophys. Res.

Benson, C. S. 1962. Stratigraphic studies in the snow and firn of the Greenland ice sheet. SIPRE Res. Rep. 70.

Budd, W. F. and T. H. Jacka. 1989. A review of ice rheology for ice sheet modelling. Cold Reg. Sci. Technol., 16(2), 107-144.

Clough, J.W. 1977. Radio-echo sounding: reflections from internal layers in ice sheets. F. Glaciol., 18(78), 3-14.

Dahl-Jensen, D. 1985. Determination of the flow properties at Dye 3, south Greenland, by bore-hole-tilting measurements and perturbation modelling. f. Glaciol., 31(108), 92-98.

Dahl-Jensen, D. and N. S. Gundestrup. 1987. Constitutive properties of ice at Dye 3, Greenland. International Association of Hydrological Sciences Publication 170 (Symposium at Vancouver 1987 - The Physical Basis of Ice Sheet Modelling), 31-43.

Dahl-Jensen, D. and 9 others. 1997. A search in north Greenland for a new icecore drill site. F. Glaciol., $\mathbf{4 3}$ (144), 300-306.

Etheridge, D. M. 1989. Dynamics of the Law Dome ice cap, Antarctica, as found from bore-hole measurements. Ann. Glaciol., 12, 46-50.

Fahnestock, M. A., W. Abdalati, S. Luo and S. P. Gogineni. In press. Internal layer tracing and age-depth-accumulationrelationships for the northern Greenland ice sheet. 7. Geophys. Res.
Fujita, S. and S. Mae. 1994. Causes and nature of ice-sheet radio-echo internal reflections estimated from the dielectric properties of ice. Ann. Glaciol., 20, 80-86.

Fujita, S. and 6 others. 1999. Nature of radio-echo layering in the Antarctic ice sheet detected by a two-frequency experiment. F. Geophys. Res., 104(B6), 13,013-13,024.

Funk, M., K. Echelmeyer and A. Iken. 1994. Mechanisms of fast flow in Jakobshavns Isbræ, West Greenland: Part II. Modeling of englacial temperatures. 7. Glaciol., 40 (136), 569-585.

Hammer, C. U. 1980. Acidity of polar ice cores in relation to absolute dating, past volcanism, and radio-echoes. F. Glaciol., 25(93), 359-372.

Harrison, C. H. 1973. Radio echo sounding of horizontal layers in ice. $\mathcal{F}$. Glaciol., 12(66), 383-397.

Hofmann, W. 1975. Die Internationale Glaziologische Grönland-Expedition (EGIG). 2. Die geodätische Lagemessung-Eisbewegung 1959-1967 in den EGIG-Profilen. Z. Gletscherkd. Glazialgeol., 10(1-2), 1974, 217-224.

Huybrechts, P. and J. de Wolde. 1999. The dynamic response of the Greenland and Antarctic ice sheets to multiple-century climatic warming. $\mathcal{F}$. Climate, 12(8), 2169-2188.

Johnsen, S. J. and 14 others. 1997. The $\delta^{18} \mathrm{O}$ record along the Greenland Ice Core Project deep ice core and the problem of possible Eemian climatic instability. 7. Geophys. Res., 102(C12), 26,397-26,410.

Kostecka, J. M. and I. M. Whillans. 1988. Mass balance along two transects of the west side of the Greenland ice sheet. F. Glaciol., 34(116), 31-39.

Li Jun, T. H. Jacka and W. F. Budd. 1996. Deformation rates in combined compression and shear for ice which is initially isotropic and after the development of strong anisotropy. Ann. Glaciol., 23, 247-252.

Millar, D. H. M. 1981. Radio-echo layering in polar ice sheets and past volcanic activity. Nature, 292(5822), 441-443.

Mock, S. J. and W. F. Weeks. 1966. The distribution of 10 meter snow temperatures on the Greenland ice sheet. F. Glaciol., 6(43), 23-41.

Moore, J. C. 1988. Dielectric variability of a $130 \mathrm{~m}$ Antarctic ice core: implications for radar sounding. Ann. Glaciol., 11, 95-99.

Morgan, V., T. D. van Ommen, A. Elcheikh and Li Jun. 1998. Variations in shear deformation rate with depth at Dome Summit South, Law Dome, East Antarctica. Ann. Glaciol., 27, 135-139.

Morse, D. L., E. D. Waddington and E. J. Steig. 1998. Ice age storm trajectories inferred from radar stratig raphy at Taylor Dome, Antarctica. Geophys. Res. Lett., 25(17), 3383-3386.

Nereson, N. A., C. F. Raymond, R. W. Jacobel and E. D. Waddington. 2000 The accumulation pattern across Siple Dome, West Antarctica, inferred from radar-detected internal layers. f. Glaciol., 46(152), 75-87.

Paren, J. G. and G. de Q. Robin. 1975. Internal reflections in polar ice sheets. 7. Glaciol., 14(71), 251-259.

Paterson, W. S. B. 1994. The physics of glaciers. Third edition. Oxford, etc., Elsevier.

Russell-Head, D. S. and W. F. Budd. 1979. Ice-sheet flow properties derived from bore-hole shear measurements combined with ice-core studies. $\mathcal{F}$. Glaciol., 24(90), 117-130.

Wang,W. L. and R. C. Warner. 1998. Simulation of the influence of ice rheology on velocity profiles and ice-sheet mass balance. Ann. Glaciol., 27, 194-200.

Wang, W. L. and R. C. Warner. 1999. Modeling of anisotropic ice flow in Law Dome, East Antarctica. Ann. Glaciol., 29, 184-190.

Whillans, I. M. 1976. Radio-echo layers and the recent stability of the West Antarctic ice sheet. Nature, 264(5582), 152-155

Zwally, H. J. and A. C. Brenner. 2001. The role of satellite radar altimetry in the study of ice sheet dynamics and mass balance. In Fu, L.-L., ed. Satellite altimetry and earth sciences. New York, Academic Press Inc., 351-369. (International Geophysical Series 69.

Zwally, H. J. and M. B. Giovinetto. 2000. Spatial distribution of net surface mass balance on Greenland. Ann. Glaciol., 31, 126-132. 